trumento de intervenção sobre a realıdade.

Por isso, parece sobretudo necessário, qualquer que seja o conjunto de questőes e linha de desenvolvimento meto. dológico a ser perseguido no âmbito do setor, que seja dada ênfase numa identificação explícita dos pressupostos, quantitativos ou qualitativos, da análise e num tratamento não deterministico das previsões.

\section{NOTAS}

1. Constata-se, por exemplo, in iciativas neste sentido de parte da ELETROBRÁS, FUR. NAS, CESP e CEMIG.

2. Ver, por exemplo, os documentos NT-13, NT.20 e IT .447 do DEME/Eletrobrás.

3 Os modelos citados estäo implantados ou em vias de implantação na CESP (MEDEE) e naELETROBRÁS (MEDEE e MARKAL).

4. Ver, por exemplo, diversos estudos que têm se desenvolvido em FURNAS (Asses. soria de Estudos Económico-Energéticos/ Diretoria Técnica e na ELETROBRÄS (AESP e DEME/DPE), com base no em. prego da matriz de insumo-produto brasileira.

5. O Modelo Setorial está sendo desenvolvido sob a coordenação da ELETROBRÁS, dentro de uma programação conjunta do DNAEE e ELETROBRÁS, com participa. ção das principais empresas concessioná. rias.

\title{
Modelos de análise da demanda global de energia: uma descrição geral e avaliação
}

\section{JAYME PORTO CARREIRO FILHO JOÃO ALBERTO VIEIRA SANTOS MARIA TERESA FERNANDES SERRA RUDERICO FERRAZ PIMENTEL}

Jayme Porto Carreiro Filho é engenheiro no Economic Studies Section, Division of Nuclear Power, International Atomic Energy Agency. Tem doutoramento em Engenharia de Produção pela Universidade de Birmingham, Inglaterra.

João Alberto Vieira Santos é analista de pesquisa operacional do Servico de Planejamento da PETROBRÁS, com curso de pós-graduação em Planejamento Energético, COPPE, Universidade Federal do Rio de Janeiro.

Maria Teresa Fernandes Serra é analista de mercado do Departamento de Mercado da ELETROBRÁS. Tem mestrado em Planejamento Urbano e em Economia pela Universidade da California, Berkeley, EUA.

Ruderico Ferraz Pimentel é gerente da Divisão de Estudos Económico-Financeiros da Companhia Internacional de Seguros. Tem doutoramento em Programação Matemática pela London Schoool of Economics and Political Science, Inglaterra.

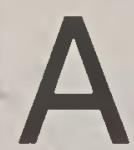

significativa mudança por que vem passando o setor energético, a partir da década de 70 gerou a necessidade de desenvolvimento de novas metodologias de projeção da demanda de energia. Os modelos tradicionais usados até esta época eram voltados para mercados de uma só fonte de energia, agregados ou enfocando œrto segmento consumidor (residencial, industrial, etc.) ou tipo de uso (cocção, aquecimento, etc.), e têm como uma limitação importante a sua na. tureza deterministica, oriunda na extrapolação de tendências, através do uso predominante de econometria, que faz com que sejam projetados para o futuro padrōes de comportamento observados no passado.

A partir do desenvolvimento do MEDEE (Modele d'Evolution de la Demande d'Energie) pelo IEJE (Institut Economique et Juridique de l'Energie) de Grenoble em 1976, tem-se visto o aparecimento de muitos modelos que, de maneira semelhante, simulam a evolução da demanda de energia global de um sistema sócio-econômico. Esta metologia, baseada na técnica de construção de cenários, vem se constituindo numa alternativa cada vez mais utilizada para os estudos de previsão, especiálmente onde se reconhecem ou se julga que poderão ocorrer mudanças estruturais sin nificativas nos padrōes de consumo energético. Nestes casos, a análise da demanda deve retratar conjunto numeroso de influências de natureza variada - econômica, compor tamental, tecnológica ou política - envolvendo alto grau de interdependência e incerteza. Os modelos de energia global não só produzem uma projeção de demanda incorporando o efeito de diferentes estratégicas de abastecimento energé tico e politicas de desenvolvimento económico, como procuram explicar claramente os impactos destas.

Este artigo descreve primeiramente a estrutura típica e o funcionamento dos modelos de energia global. Em seguida, discute suas vantagens e limitações como enfoque metodológico nos estudos de previsão da demanda de energia ao longo prazo.

Estrutura e funcionamento de um modelo de energia global

Os modelos de energia global basseiam-se em duas idéias fundamentais. Primeiro, não existe determinismo nem na evolução da economia, nem nas rela. çōes entre crescimento econômico e a evolução da demanda de energia a longo prazo. Asşim, é necessário uma nova atitude na atividade de previsão, que consiste em explorar futuros possiveis e razoáveis e as condições em que eles poderão ocorrer. Segundo, a complexidade das relações entre crescimento económico e evolução da demanda de energia não pode, a longo prazo, ser escondida através de relaçōes agregadas. Uma detalhada análise dos mecanismos de formação e evolução da demanda de energia é, portanto, requerida.

Essas premissas metodológicas levam a uma análise desagregada do sistema sócio-econômico e da demanda de energia e a uma descrição das possiveis evolu. ções deste sistema. Dois conceitos utilizados na análise da demanda são os de energia útil e final, que são repassados na Figura 1, onde são relacionados com os de energia primária e secundária. 
A demanda de energia deriva das necessidades reais ou subjetivas dos individuos, como a mobilidade e o conforto, ou então de atividades econômicas, como a produção de aço ou o transporte de carga. Convém expressar tais necessidades em termos de energia útil, uma vez que os individuos e as atividades requerem, por exemplo, a energia que thes permita realizar determinado "serviço", como locomover-se, iluminar ambientes ou gerar vapor industrial, e năo de gasolina e eletricidade especifica. mente, que constituem duas formas de energia, embora não as únicas, através das quais se satisfazem as necessidades ou se realizam os "serviços" referidos. Em geral, a satisfação de necessidades ou a realização de "serviços" que envol. vem o consumo de energia é alcançada através do uso de um equipamento (au tomóvel, lâmpada ou caldeira) que converte energia final em energia útil, mediante processos com determinada eficiência, variável de um equipamento e processo para outro.

Nesses casos, diversas formas de energia competem pelo mercado consumi-

\section{FIGURA 1}

8

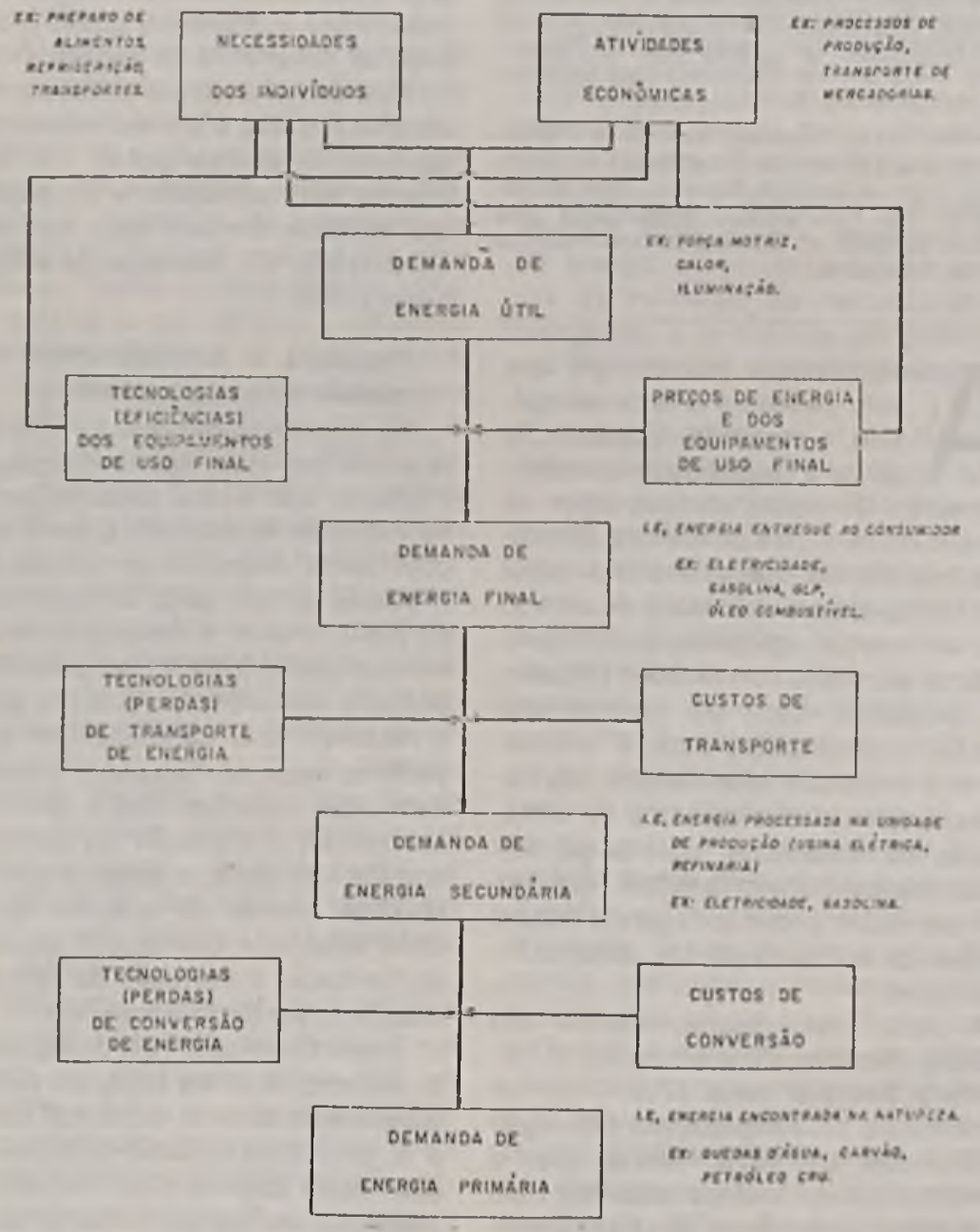


dos, etc.) em funçao de seus principais de term inantes. De modo geral, a demanda é especificada como: onde:

$$
C E=A \times I E \times P E \times E
$$

$C E=$ consumo de energia final

$A=$ indicador de atividade

$I E=$ coeficiente de intensidade energética, final ou útil, conforme o segmento

$P E=$ participação de cada forma de energia no atendimento das demandas não especificas ou cativas (especificadas em energia útil)

$E=$ eficiência do processo de transformação de energia final em útil.

Uma vez que a demanda de energia num setor, como indicado acima, deriva dos "serviços" desenvolvidos no âmbito daquele setor, sejam deprodução (atividades econômicas) ou de consumo (necessidades de individuos e famílias), a ava. liação da demanda de energia requer o prévio dimensionamento de um indica. dor de atividade ou dos serviços do setor, expresso em termos físicos ou financeiros (população ou domicílios, valor adicionado ou volume de produção de bens e serviços). O Quadro 2 apresenta indicadores de atividades que poderão ser utilizados por setor de consumo num modelo de energia global que tenha a desagregação setorial mostrada no Quadro 1.

Para o transporte de passageiros, a demanda total, no exemplo, poderá ser desagregada por tipo de percurso (urbano/interurbanol e por modo ou tipo de equipamento (individual, coletivo: ônibus, trem, avião), através de participações dos passagairos.kms a serem transportados. Para o transporte de carga, neste exemplo, desagrega-se apenas por modo. Em ambos os casos, o indicador de atividade é dimensionado utilizando-se uma abordagem pelo lado da demanda pela atividade ou serviço de transportes, ou seja, envolve uma avaliacão direta das necessidades de deslocamento (pass. $\mathrm{km}$ e ton. $\mathrm{km}$ ) caracter is. ticas de indivíduos e atividades em distintos cenários. Alternativamente, pode rá ser adotada uma abordagem pelo la do da oferta dos serviços de transportes. Neste caso, o indicador de atividades é dimensionado através da disponibilidade de equipamentos utilizados no atendimento da demanda por estes serviços, ou seja, através da avaliação da frota de
QUADRO 1

\section{MODELOS DE ENERGIA GLOBAL}

\section{DESAGREGAÇĀO SETORIAL E TIPOS DE USO DE ENERGIA EXEMPLO}

\begin{tabular}{|c|c|c|}
\hline SETOR DE CONSUMO & \multicolumn{2}{|c|}{ USO DE ENERGIA } \\
\hline Agricul tura & usos especificos: & $\begin{array}{l}\text { combustive is motores } \\
\text { combustive is fosseis } \\
\text { eletricidade }\end{array}$ \\
\hline $\begin{array}{l}\text { Indústria } \\
\text { (básica e nāo básica) }\end{array}$ & $\begin{array}{l}\text { usos especificos: } \\
\text { usos térmicos: }\end{array}$ & $\begin{array}{l}\text { combustive is motores } \\
\text { combustiveis fósseis } \\
\text { eletricidade } \\
\text { fornos e aquecimento direto } \\
\text { vapor e água quente } \\
\text { coque para siderurgia } \\
\text { consumo não energético }\end{array}$ \\
\hline Serviços & $\begin{array}{l}\text { usos específicos: } \\
\text { usos térmicos }\end{array}$ & $\begin{array}{l}\text { eletricidade } \\
\text { ar condicionado }\end{array}$ \\
\hline Residencial & usos especificos: & $\begin{array}{l}\text { eletricidade } \\
\text { ar condicionado }\end{array}$ \\
\hline Transporte de carga & $\begin{array}{l}\text { coç্̄o } \\
\text { agua quente } \\
\text { combust ivel motor: }\end{array}$ & $\begin{array}{l}\text { caminhão } \\
\text { trem diesel } \\
\text { barco } \\
\text { duto }\end{array}$ \\
\hline 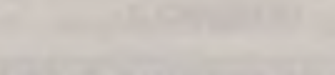 & $\begin{array}{l}\text { carvâo: } \\
\text { eletricidade: }\end{array}$ & $\begin{array}{l}\text { trem a vapor } \\
\text { trem elétrico }\end{array}$ \\
\hline Transporte de passageiros & combustivel motor: & $\begin{array}{l}\text { carro } \\
\text { ônibus } \\
\text { avião } \\
\text { trem diesel }\end{array}$ \\
\hline 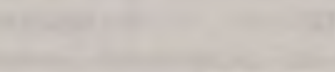 & $\begin{array}{l}\text { carvāo: } \\
\text { eletricid ade: }\end{array}$ & $\begin{array}{l}\text { trem a vapor } \\
\text { trem elétrico }\end{array}$ \\
\hline
\end{tabular}

QUADRO 2

\section{MODELOS DE ENERGIA GLOBAL INDICADORES DE ATIVIDADE \\ EXEMPLO}

\begin{tabular}{|c|c|c|c|}
\hline Setor de Consumo & Indicador & Unidade & Determinaçāo do Ind icador \\
\hline $\begin{array}{l}\text { Agricultura } \\
\text { Indústria }\end{array}$ & $\begin{array}{l}\text { Produto setorial } \\
\text { Produto setorial }\end{array}$ & $\begin{array}{l}\text { USS } \\
\text { USS }\end{array}$ & $\begin{array}{l}\text { PIB } \times \% \text { setorial } \\
\text { PIB } \times \% \text { setorial }\end{array}$ \\
\hline Serviços & $\begin{array}{l}\text { No de trabalhadores } \\
\text { no setor serviços }\end{array}$ & - & Pop. $\times$ PEA/Pop $\times$ PEAss\$PEA \\
\hline Residencial & NO de domicilios & $\longrightarrow$ & Pop. $\div$ hab/dom \\
\hline $\begin{array}{l}\text { Transporie de } \\
\text { carga }\end{array}$ & $\begin{array}{l}\text { Necessidade de } \\
\text { transporte dos }\end{array}$ & & \\
\hline & $\begin{array}{l}\text { setores agricultura } \\
\text { e indústria }\end{array}$ & tok.km & PIB (total menos serviços) $\times$ t. $\mathrm{km} /$ USS \\
\hline $\begin{array}{l}\text { Transporte de } \\
\text { passageiros }\end{array}$ & $\begin{array}{l}\text { Necessidades de } \\
\text { transporte dos } \\
\text { individuos }\end{array}$ & pass.km & Pop. $\times$ pass.km/ab \\
\hline
\end{tabular}

-PEA - populacão economicamente ativa. 
ve ículos de cada tipo, caracter ística dos diversos cenários.

Esta opção entre uma abordagem pelo lado da demanda ou da oferta dos serviços característicos dos setores consumidores de energia lou ainda uma conjugação destas duas) se verifica não só com relação aos transportes, como também na análise dos demais módulos setoriais.

Alguns exemplos de coeficientes de intensidade energética estão indicados de maneira simplificada no Quadro 3. Os modelos distinguem tipicamente entre dois casos: um primeiro em que a demanda de energia só pode ser provida ou constitui mercado cativo de uma única forma de energia (combustiveis líquidos para caminhão; eletricidade para iluminação), ou ainda, casos onde, embora provida por diferentes energéticos, a distinção entre estes seja pouco importante em termos do tipo de aná. lise que o modelo se propõe a fazer; e um segundo em que várias energias concorrem no atendimento da demanda (usos térmicos na indústria, nos serviços e no setor residencial; participação dos diversos combustíveis líquidos no atendimento à demanda no setor transportes) devendo, portanto, a análise distinguir entre elas.
No primeiro caso, a demanda é espe cificada em termos de energia final e o cálculo da demanda se reduz a $A \times I E$ em (1), uma vez que a participação $P E$ assume valor unitário e a relação que expressa a eficiência média do processo de conversão da energia final em útil pode ser incorpor ada no cálculo do coeficiente de intensidade energética. Já no caso em que ocorre competição entre energéticos, o coefiente de intensidade energética é dado em termos de energia útil, requerendo-se a seqüência integral de cálculo indicada em (1), para que se estabeleça a participação e eficiência de cada tipo de energia. Para estes casos, é, em geral, admitido o a tendimento da demanda de energia útil através de eletricidade, diversos combustiveis fósseis, energia solar e combustiveis não comerciais, etc., conforme o segmento de consumo e o tipo de ênfase do modelo.

A equação (1) mostra, portanto, que a demanda de energia pode ser expressa em termos de energia útil ou final. $E$, em geral, expressa desta última forma quando o mercado ou é cativo ou quan. do a competição entre energéticos não é significativa. Caso contrário, especificase a demanda em termos úteis. As necessidades de energia são então particionadas pelas diversas formas de energia atra- vés de PE e transformadas em energia $\dagger$ nal através de uma relação de rendimen. tos que expressa a eficiência do processo típico de transformação associado a ca. da energia no segmento de consumo em questão.

A análise da competicão entre energéticos, e a conseqüente divisão do atendimento da demanda de energia útil, poderá ser feita de diversas formas que estão diretamente associadas ao tipo de desagregação adotada e à hierarquiza. ção observada nesta desagr egação, sobre. tudo no tocante à incorporação dos equipamentos à análise. Assim, por exemplo, se os equipamentos são definidos tendo em vista já o tipo de energía que utilizam (carro a álcool, caminhão diesel, etc.), o coeficiente de intensidade energética, ou consumo específico. será dado diretamente em termos de energia final para o carro a álcool, caminhão diesel, etc. Neste caso, a competição entre energéticos está subordinada a uma prévia análise da competição entre tipos de equipamentos.

No entanto, os equipamentos poderão ser definidos independente da energia a ser utilizada. Neste caso, o coeficiente deverá ser dado em termos de energia útil, ou seja, será especificado em termos da forma de energia de uso

QUADRO 3

\section{MODELOS DE ENERGIA GLOBAL COEFICIENTES DE INTENSIDADE ENERGÉTICA EXEMPLOS}

\begin{tabular}{|c|c|c|c|c|c|c|}
\hline SETOR DE CONSUMO & TIPO DE USO & COEFICIENTE & UNIDADE & \multicolumn{3}{|c|}{ DETERMINAÇĀO DO COEFICIENTE } \\
\hline Agriaultura & combustivel motor & $\begin{array}{l}\text { intensidade do consumo de } \\
\text { combustivel motor, por uni- } \\
\text { dade de produto }\end{array}$ & $\begin{array}{l}\text { kWh/US\$ } \\
\text { (energia final) }\end{array}$ & & & \\
\hline Indüstria & vapor e água quente & $\begin{array}{l}\text { intensidade do consurno de } \\
\text { energia na produção de va- } \\
\text { por e água quente naindús- } \\
\text { tria, por unidade de produto }\end{array}$ & $\begin{array}{l}\text { kWh/US\$ } \\
\text { (energia útil) }\end{array}$ & $\begin{array}{l}\text { intensidade do con- } \\
\text { sumo de energiana } \\
\text { producão de calor } \\
\text { industrial } \\
\text { (kWh/uS\$) }\end{array}$ & $x$ & $\begin{array}{l}\% \text { do vapor e } \\
\text { água quente na } \\
\text { demanda por ca- } \\
\text { lor industrial }\end{array}$ \\
\hline Servicos & $\begin{array}{l}\text { eletricidade especi- } \\
\text { fica }\end{array}$ & $\begin{array}{l}\text { intensidade do consumo de } \\
\text { eletricidade, por trabalhador }\end{array}$ & $\begin{array}{l}\text { kWh/trab. } \\
\text { (energia final) }\end{array}$ & & & \\
\hline Residencial & água quente & $\begin{array}{l}\text { intensidade do consumo de } \\
\text { energia, por domicílio }\end{array}$ & $\begin{array}{l}\text { kWh/dom. } \\
\text { (energia útil) }\end{array}$ & $\begin{array}{l}\text { \% dos domicflios } \\
\text { servidos }\end{array}$ & $\mathbf{x}$ & $\begin{array}{l}\text { intensidade do } \\
\text { consumo de ener- } \\
\text { gia no aqueci- } \\
\text { mento de agua } \\
\text { (kWh/dom.) }\end{array}$ \\
\hline Transporte de carga & $\begin{array}{l}\text { combustivel motor } \\
\text { em caminhões }\end{array}$ & $\begin{array}{l}\text { intensidade do consumo de } \\
\text { combustiveis líquidos, por } \\
\text { t. km. transportado em cam. }\end{array}$ & $\begin{array}{l}\mathrm{kWh} / \mathrm{t.km} \\
\text { (energia final) }\end{array}$ & & & \\
\hline Transporte de passageiros & $\begin{array}{l}\text { combustivel motor } \\
\text { em ónibus urbanos }\end{array}$ & $\begin{array}{l}\text { intensidade do consumo de } \\
\text { combustiveis liquidos por } \\
\text { pass. km transportado em } \\
\text { onnibus }\end{array}$ & $\begin{array}{l}\text { kWh/pass. km } \\
\text { (energinal final) }\end{array}$ & & - & - \\
\hline
\end{tabular}


preponderante naquele tipo de equipamento, sendo esta então tratada como uma energia de referência (nos dois exemplos acima, a gasolina e o próprio diesel). Assim, para se chegar ao consumo final, definido inclusive por forma de energia utilizada, será necessário particionar o consumo do segmento, contabilizado em termos da forma de ener. gia de referência, levando-se em conta a relação de rendimentos entre a energia de referência e aquela efetivamente caracteristica do segmento.

\section{2) Funcionamento dos modelos}

A maioria dos modelos de energia global requer a entrada de conjuntos de 150 a 300 dados para cada ano a ser analisado. Um conjunto descreve o ano base e os demais traduzem os cenários considerados para os anos intermediários e final. Por hipótese, para um estu. do com horizonte de 30 anos, poderá ser adotada uma abertura decenal ou qüinqüenal. Como unidades contábeis mais freqüentes săo utilizados valores monetários constantes e valores de energia expressos na unidade caracteristica de uma única forma de energia tomada como referência, por exemplo, MWh ou tEP.

Os modelos fornecem, como resultado, quadros contendo, nos anos especificados, o consumo de energia final por setor de consumo e tipo de energia, além de outros indicadores de suporte à análise destes resultados, tais como - consumo de energia útil em usos sujeitos à competição entre energéticos ou os coeficientes de intensidade energética por setor e tipo de energia.

$\mathrm{Na}$ especificação dos cenários para o ano final, pode-se proceder da seguinte maneira. Identificam-se inicialmente quais os parâmetros mais influentes, ou seja, aqueles que explicam parcelas sig. nificativas da demanda no ano base. Com isto consegue-se separar um menor número de variáveis que merecem um cuidado especial na projeçăo.

Em seguida, preparam-se cenários de referência para o ano final e os intermediários. São novamente examinados, de in ício, os parâmetros mais significativos. Tendo em vista uma rela tiva inércia dos sistemas sócio-económicos, a maior parte deste coincide com os identifica. dos no ano inicial. Deverá ser destacado, no entanto, um conjunto adicional de parâmetros que apresentam uma participação crescente de usos tradicionais, cujo processo de penetração ainda se encontra em fase inicial (como o condicionamento de ambientes) ou usos emergentes de energia (como a energia solar). Estes parâmetros também reque. rerão mais estudo na preparação dos cenários, em especial quanto à sua evolução ao longo do per íodo.

Num terceiro momento, são construídos cenários alternativos para o crescimento da demanda, mediante a varia. cão de hipóteses quanto à evolução dos principais parâmetros e outros a eles associados diretamente (como nos casos em que a penetração de determinada energia é dada através de participações). Dentre os parâmetros principais, deverão ser revistos aqueles que tendem a ter variaçåo significativa durante o periodo (como o produto ou a população) ou, por outra, aqueles que, embora mais estáveis, apresentem forte repercussão sobre a estimativa da demanda (como as participaçōes da indústria básica e não básica no PIB), por se vincularem a segmentos de elevada intensidade de con. sumo unitário.

O resultado deste modelo poderá ter algumas parcelas de demanda especifica. das em energia útil, sendo utilizado por um modelo de oferta que forneceria as alternativas de atendimento do mercado de energia e identificaria elementos co. mo o investimento necessário, possibilitando um processo interativo de análise com o modelo de demanda e os cenários macroeconômicos em que este se baseia.

Não sendo utilizado um modelo de oferta, convém que se faça uma estimativa do investimento requerido para preparar o setor energético para atender à demanda prevista, acrescido do custo da eventual importação de energia. Este montante deverá ser compatível com as hipóteses de crescimento econômico assumidas pelo cenário. Se os dispêndios associados à provisão de energia são considerados excessivos para o tipo de cres. cimento econômico suposto, o cenário deverá ser reescrito. Neste caso, o crescimento do PIB deverá ser mais lento e/ou a economia deverả ser menos intensiva energeticamente, o que significa, por sua vez, uma redefinição da estrutura setorial de produção ou a suposição de um aumento de eficiência energética.

Este tipo de ajuste na definição dos cenários alternativos aponta na direção de medidas ou que deveriam ser objeto de formulação de politicas energéticas. mediante alocação de recursos ou regulamentação do consumo ou produção. ou que, embora fora do âmbito da ação do setor energético, deverão condicionar fortemente as possibilidades de atendi. mento da demanda e, portanto, deverão ser discutidas e acompanhadas com especial interesse pelo setor.

Vantagens e limitaçōes dos modelos de previsão da demanda de energia global

Os modelos de energia global podem ser caracterizados como planos de contas detalhados da demanda de energia, em geral adotando um enfoque hierárquico no tratamento dos paráme tros utilizados. Tal abordagem metodológica domina a grande maioria dos madelos mais recentes e parece ser a mais adequada a um tratamento analítico do problema da previsâo de demanda num contexto de potencial mudança dos determinantes estruturais do consumo e de incerteza quanto à oferta de fontes energéticas e à evolução da atividade econômica em gerał.

E importante salientar, no entanto. que este tipo de modelo abarca apenas parcialmente a formalização da previsão da demanda de energia, uma vez que freqüentemente trata os indicadores lou os fatores determinantes destes) como parâmetros a serem definidos exogenamente para cada setor. Grande parte da dificuldade da projeção da demanda de energia consiste precisamente na definicão de uma abordagem adequada para a projeção destes indicadores ou seus de. terminantes, cada um dos quais requer considerações metodológicas específicas. A ausência de um tratamento formalizado dentro de um modelo para es sa projeção faz com que o estudo de ca. da setor vá requerer do usuário um es forco de desenvolvimento metodológico extremamente elevado, o que näo é de in icio aparente na leitura de um modelo contábil genérico:

Por outro lado, possivelmente uma grande parte da generalidade minima que se pode alcançar num modelo de demanda deste tipo provém dessa não au tomatização da projeção dos parâmetros. Esta etapa é fortemente dependente dos dados primários que se tenha disponiveis, assim como das caracteristicas estruturais do país ou região. Enquanto que para a organização contábil da demanda se pode pretender algum $\mathrm{ni}$ vel de generalidade, para a projeção dos parâmetros isto se torna mais dificil.

Embora os modelos de energia global facilitem o reconhecimento da multiplicidade de fatores que, em maior ou me. nor grau, determinam a demanda futura de energia, atenção explícita é dada so- 
bretudo a fatores tecnológicos e, até certo ponto, econômicos. Assim, os modelos não incorporam diretamente variáveis de ordem político-institucional ou variáveis econômicas, como distribuição de renda e preços. Qualquer análise que, explicitamente, incorpore este tipo de variável deverá ser feita em paralelo aos modelos propriamente ditos, quando da formulação dos cenários.

No tocante a variáveis de ordem econômica, isto significa que um esforço de coerência grande, e facilmente omitido, deve ser desenvolvido na estimativa de indicadores de produção, de intensidade energética, de penetração de tipos de tecnologia e formas de energia final, de modo a traduzir e buscar consistência, não só quanto a estilos de crescimento e organização da produção, mas também quanto à influência do fator preços na competição entre energéticos.

É desejável, portanto, que esteja associado ao modelo de previsão da demanda um modelo macroeconômico de longo prazo que identifique um conjunto de parâmetros que expressem as principais articulações entre o setor energético e os demais setores da economia e que vão além meramente, dos parâmetros de produção normalmente utilizados como indicadores de atividade. Um modelo macroeconômico, aliás, poderia informar ou permitira uma avaliação dos resultados não só da análise feita para a demanda como também da de oferta de energia. Por isso deveria ser visto como componente essencial de um sistema de modelos de planejamento energético.

Por outro lado, a descrição dos processos tecnológicos de consumo de energia é, em geral, ainda bastante agregada. O fato de não ser contabilizado o estoque de capital envolvido em cada processo de consumo em alguns setores, como, por exemplo, o industrial, limita a análise das possibilidades de substituição e torna difícil distinguir entre a substituição entre energéticos alternativos numa mesma tecnologia de consu. mo, sem alterações do processo de produção e aquela em que ocorrem mudancas de tecnologia de consumo, envolvendo efetivamente alterações no processo produtivo. Para os segmentos de consumo em que as possibilidades de substituição são significativas, uma explicitação dos estoques de cada tipo de equipamento e, em particular, da parcela renovada a cada período, permitiria uma melhor aproximação da parcela de substituição de energia que poderá ser atingida e das precondições para que esta seja alcançada.

Apesar de haver diversas alternativas para realizar-se a previsão de demanda, de ser conveniente muitas vezes a utilização de mais de uma forma de estimativa e das diferenças significativas que existem entre países desenvolvidos e subdesenvolvidos, países de clima frio e quente, etc., as versões existentes dos modelos globais de energia são programados de maneira bastante rígida, não permitindo ao usuário uma redefinição, mesmo que parcial, da setorização. Não obstante as dificuldades, algum nivel de generalidade pode e deve ser introduzido num modelo de demanda. A formulação, embora voltada a um tipo básico de estruturação do consumo, deve ser capaz de permitir, dentro destes limites, o máximo de flexibilidade ao usuário.

Numa linha de eventual aprimoramento via redefinição dos modelos hoje disponiveis, convém considerar a possibilidade de se adotar uma formulação que se componha de uma série de "meto. logias de projeção" alternativas, cabendo ao usuário escolher as equações mais adequadas ao estudo específico que tiver em pauta. Esta filosofia se fundamenta na verificação de que a previsão de demanda não deve ser encarada de maneira mecânica: um sistema aberto que permita ao usuário testar diferentes hipóteses pode propiciar uma melhor interação entre o conhecimento armazenado e automatizado pelo modelo e a "expertise" do usuário. As relações que não fossem utilizadas para a estimativa de demanda seriam sempre calculadas como controle dos resultados do modelo, buscando quer uma verificação das projeçōes básicas, quer a sua coerência com o cenário econômico e/ou energético preconizado.

Seria desejável ainda que fosse garantida flexibilidade no tocante à escolha dos setores consumidores a serem estudados, à escolha de formas de energia utilizadas e à possibilidade de entrar ou não com todos os parâmetros nos anos intermediários. Caso não houvesse conveniência de se entrar com estes valores, o modelo poderia interpolá-lo segundo critérios que o usuário escolheria.

Usualmente, os estudos de longo pra. zo constituem subsídio ao planejamento energético. Conseqüentemente, o modelo deverá não só produzir previsőes, como também permitir a análise dos efeitos de diferentes políticas energéticas e estratégias de desenvolvimento econômico, indicando tão claramente quan- to possivel qual seu impacto. A identı ficação explícita de variáveis "políticas" permite, aliás, destacar que a evolução futura do sistema energético é passivel de ser influenciada por ações correntes, ou mesmo, depende fundamentalmente de decisões tomadas no presente. No caso específico da demanda, isto significa o reconhecimento de que sua evolução pode, até certo ponto, ser orientada em direção a uma configuração desejada. Este tipo de pressuposto na formulação dos planos de desenvolvimento setorial é especialmente importante num quadro de escassez de recursos.

Já se disse que a técnica de elaboração de cenários substitui relações econométricas duvidosas por opiniōes duvidosas. Os modelos de simulação que utilizam esta técnica envolvem a formulação de hipóteses sobre o futuro de forma não extrapolativa, não determinística. Para derivação de valores futuros dos parâmetros do modelo são válidos numerosos métodos como, de fato, a avaliação subjetiva de técnicos em áreas diversas, mas também a inferência a partir, por exemplo, de resultados de levantamentos de campo, a dedução a partir de modelos analíticos, etc. Por outro lado, o reconhecimento das limitações inerentes às técnicas clássicas de previsão da demanda não implicam em sua rejeição, uma vez que complementam a elaboração de cenários, fornecendo indicadores parciais para sua construçāo. 0 que se percebe é que, pelo fato dos modelos de energia global serem abrangentes e desagregados, tendem a tornar mais transparentes as premissas utilizadas na previsão da demanda, mesmo reconhecendo-se, como mencionado acima, que a estimativa de um grande número de indicadores é feita fora do modelo propriamente dito. Permitem, portanto, que se lide com incertezas de forma mais explícita.

A transformação dos mercados de energia, desde a década de 70 , tem ocasionado uma forte interdependência na delimitação efetiva destes mercados, que deverá encontrar tradução nos estudos de planejamento do setor energético. Isto implica num questionamento quanto ao atual significado dos tradicionais determinantes do comportamento da demanda e na identificação de determinantes que deverão ter expressão daqui para a frente. Em outros termos, para que se formule previsões da evoluçäo da demanda relevantes aos estudos de planejamento dos sistemas energéticos ho- 
je, torna-se necessário que se procure um melhor entendimento das relações que vigoram entre os diversos sistemas de suprimento e consumo de energia, tendo em vista a delimitaçäo, se possi. vel, não só eficiente, mas equitativa, do mercado de cada forma de energia, associada à identificação clara de um conjunto de instrumentos de politica energética. A despeito das limitações e tendo em vista as possibilidades de aprimoramento apontadas acima, os modelos de energia global e a utilização da técnica de formulação de cenários parece constituir a abordagem, no momento, mais favorável a que se alcance este objetivo.

\section{Comentário final}

Os modelos de energia global procuram apontar para a relação multidimensional entre a evolução da demanda de energia e a dos sistemas sócio-econômi$\cos$. Enquanto instrumentos de previsão tornam bastante claro que a qualidade dos resultados é conseqüência direta da qualidade da descrição do sis tema sócioeconômico subjacente. Neste objetivo, permitem avaliar o impacto de perturbaçōes (como aumentos bruscos de precos de energia, cortes de fornecimento, inovação tecnológica), que não são usualmente tratadas nas anălises de na. tureza tendencial.

Mais do que isto, no entanto, permitem um melhor entendimento da estru. tura e inter-relação entre os componentes dos sistemas energéticos, ajudando a percepção de áreas de desconhecimento ou incerteza nos estudos de demanda e, dentre estas, as que merecem mais atenção, estudo e pesquisa.

A abordagem metodológica exposta parece ser especialmente relevante como ferramenta auxiliar de planejamento energético, uma vez que procura expressar, em termos de demanda, o efeito de políticas sociais, econômicas e tecnológicas e explorar modalidades alternati. vas de suprimento energético. Pela sua abrangência, propicia a identificação de possiveis contradiçōes e inconsistências que podem resultar destas politicas, facilitando uma tomada de decisões fundamentada no campo energético.

$\mathrm{Na}$ sua utilizaçăo, no caso brasileiro, os modelos de energia global podem e devem ser reformulados para retratar de maneira mais adequada as condições em que a demanda de energia é determinada. Cabe considerar, sobretudo, a introdução de flexibilidade quanto à es. pecificacão dos setores de consumo e formas de energia a estudar e quanto a al ternativas a serem adotadas para o cálculo da demanda. Como instrumentos de planejamento dos sistemas de suprimento energético, os modelos de demanda deverão não só estar associados a modelos de análise da oferta de energia, como também a modelos de crescimento econômico no longo prazo.

\section{BIBLIOGRAFIA}

1. BASILE, P.S. (1980), The IIASA Set of Energy Models: Its Design and Application. Laxemburg, Austria.

2. CHATEAU, B., e B. LAPILLONE (1977), La prevision a long terme de la Demande d'Energie - Propositions Methodologiques. Paris: CNRS-IEJE.

3. GIROD, J. (1977), La Demande d'Energie: Methodes et Techniques de Modelisa. tion. Paris: CNRS.IEJE.

4. IAEA (1983), Model for analysis of the energy demand (MAED) - User's Manual. Viena, Austria.

5. MIGUEZ, J.D.G., R.N.S. VALLE e R.F. PIMENTEL (1982), 'Proposta de Desenvolvimento de um Sistema de Mo. delos para o Planejamento Energético Nacional", em SETEC/MME, Relatorio Final do Grupo de Análise de Metodologia de $B$ alanço Energético e de Modelos de Planejamento Energético.

6. SANTOS, J.A.V., M.T.F. SERRA, R.P SILVA e R.F. PIMENTEL (1983), Proposta Preliminar de um Modelo de De manda Global de Energia: Setores Residencial e Transportes, Relatório apresentado no Seminário de Modelos de Demanda promovido pela OLADE, Quito, Equador, Novembro 1983.

7. SERRA, M.T.F., e J.A.V. SANTOS (1985), Brazil: Energy Demand in 2010, Relatório preparado para IAEA, Viena, Austria.

8. STANCESCU, I.D. (1985), Energy and Nuclear Power Planning in Developing Countries. IAEA, Viena, Austria. 